\title{
Plasma Cell Leukemia: Definition, Presentation, and Treatment
}

\author{
Michael Tveden Gundesen ${ }^{1} \cdot$ Thomas Lund $^{1} \cdot$ Hanne E. H. Moeller ${ }^{2} \cdot$ Niels Abildgaard $^{1,3}$
}

Published online: 28 January 2019

(C) The Author(s) 2019

\begin{abstract}
Purpose of Review We discuss current topics on the definition of plasma cell leukemia and the distinction between plasma cell leukemia and multiple myeloma. Moreover, we review the latest literature on how to treat plasma cell leukemia.

Recent Findings Plasma cell leukemia is clinically and genetically distinct from multiple myeloma. Plasma cell leukemia is defined by the observation in blood of more than $20 \%$ clonal plasma cells by differential count of the leucocytes or by counting more than $2 \times 10^{9}$ per liter circulating clonal plasma cells. However, patients with lower levels of circulating plasma cells have the same adverse prognosis, which challenges the disease definition. Survival has improved after implementation of high-dose chemotherapy with stem-cell support, bortezomib, and lenalidomide in the treatment; yet, the prognosis remains poor. The results of allo-transplants have been disappointing.

Summary The diagnostic criteria of PCL are currently discussed in the international myeloma community. Despite some improvement in survival, the prognosis remains adverse. New, more targeted treatment modalities, including immunotherapies, will hopefully improve the outcome in the near future.
\end{abstract}

Keywords Plasma cell leukemia $\cdot$ Diagnosis $\cdot$ Molecular biology $\cdot$ Cytogenetics $\cdot$ Treatment $\cdot$ Prognosis

\section{Introduction}

Plasma cell leukemia (PCL) is a rare and aggressive form of leukemia and plasma cell dyscrasia. PCL can be divided into primary PCL (PCL) and secondary PCL (sPCL) following

This article is part of the Topical Collection on Leukemia

Niels Abildgaard

niels.abildgaard@rsyd.dk

Michael Tveden Gundesen

michael.tveden.gundesen@rsyd.dk

Thomas Lund

thomas.lund2@rsyd.dk

Hanne E. H. Moeller

hanne.moeller@rsyd.dk

1 Department of Hematology, Odense University Hospital, Kloevervaenget 10, 12th floor, DK-5000 Odense C, Denmark

2 Department of Pathology, Odense University Hospital, JP Winsløvs vej 15, 2th floor, DK-5000 Odense C, Denmark

3 Department of Clinical Research, University of Southern Denmark, Odense, Denmark previously diagnosed multiple myeloma (MM); the latter typically occurring at a late and advanced stage of MM. In this review, we will primarily focus on primary PCL, but also mention SPCL, when appropriate. PCL is uncommon, but with some differences in reported incidence in different populations. In the American SEER database between 1973 and 2009, PCL accounted for approximately $0.6 \%$ of the MM cases, which translates to about 1200 patients a year in the USA [1]. In the European HAEMACARE project, the crude incidence was found to be 0.4 per million, and PCL accounted for approximately $0.5 \%$ of the MM cases [2]. These numbers are lower than earlier reported estimates of $2-4 \%$ of MM patients [3-6]. The Danish National Multiple Myeloma Registry has registered all PCL cases since 2005 [7]. It covers the entire Danish population in a country with a free and public health care system, and data completeness is almost 100\%. From 2005 to 2015, the crude Danish PCL incidence was 1.2 per million and accounted for approximately $2 \%$ of the MM cases [7]. Historically, primary PCL has been more common than SPCL. However, in recent years, the number of cases of sPCL has increased [6]. This is probably caused by the improved survival of MM; more patients live long enough for the clone to evolve into sPCL. A review from 2018 found that the prevalence of MM might have as much as tripled in recent years due to an aging population and improved survival 
[8]. Also, more MM patients receive several lines of treatment, which can potentially contribute to clonal selection and thereby co-drive the development of sPCL [9].

The prognosis of primary PCL has generally been dismal with reported median overall survival (OS) below 1 year [1]. With the use of novel treatments and autologous stem cell transplantation (ASCT), this has improved somewhat, although the prognosis remains poor. Novel treatment modalities, including immunotherapy and cellular therapy are under evaluation, and hopefully, these new technologies will show efficacy in PCL and improve the prognosis.

In this review, we will discuss some controversies in the definition of PCL and focus on clinical presentation, disease biology, and treatment.

\section{Definition and Diagnosis of Plasma Cell Leukemia}

The diagnostic definition of PCL has traditionally been based on Kyle's criteria from 1974 [10]. In this seminal paper, PCL was defined by at least $20 \%$ circulating plasma cells and a total plasma cell count in peripheral blood of at least $2 \times 10^{9} /$ 1 , thereby identifying a leukemic subtype of MM with a particularly poor prognosis. Since, this paper has provided the framework for the diagnosis of PCL [10] However, the definition is still under debate. Some studies use only one of the original two requirements to define PCL, and several recent studies question whether a lower threshold of total plasma cells might better risk classify a subgroup of MM patients. Moreover, advances in flow cytometry allow better characterization and clonality assessment of plasma cell populations [1, 11-16]. The morphology and immunophenotype of the malignant PCs in PCL, MM, and SPCL are not distinguishable. The expression of the plasma cell markers CD138 and CD38 does not differ between the groups. Nevertheless, significant differences have been observed. The adhesion molecule CD56 is more frequently found to be positive in MM, and the B cell marker CD20 is more often positive in PCL [17] (Fig. 1).

Three topics call for further discussion: (1) the need to examine for clonality of plasma cells in PCL, (2) the necessity of requiring a high percentage of circulating plasma cells as well as a total plasma cell count, and (3) defining the correct threshold for circulating plasma cells.

\section{Clonality of Plasma Cells in Plasma Cell Leukemia}

The original Kyle's criteria never described a need to investigate plasma cell clonality when defining PCL [10]. At that time, this made sense. Cell sorting, flow cytometry, and immunohistochemistry were in their absolute nascence with the first primitive electric cell sorting device being reported in
1965 [18]. Yet, we know that high amounts of circulating plasma cells are not limited to PCL, but are also observed in severe infections, mononucleosis, and serum sickness [14, 15]. Furthermore, there have been case reports of benign polyclonal plasmacytosis in other diseases, such as renal amyloidosis [16]. PCL patients also quite often present with concomitant severe infections, which may increase the number of polyclonal plasma cells $[14,15,19 \bullet, 20 \bullet, 21 \bullet, 22 \bullet, 23 \bullet, 24 \bullet]$. Therefore, clonality assessment should be included in the diagnostic work-up of plasma cell cytosis [25]. This is most efficiently done by flow cytometry.

\section{Defining the Requirements for Plasma Cell Leukemia Diagnosis}

It has been disputed if at least $20 \%$ circulating plasma cells AND a total plasma cell count of at least $2 \times 10^{9} / 1$ are required, as in the original Kyle definition, [10] or if one of these is sufficient [25]. As of now, the International Myeloma Working Group (IMWG) [25] and WHO [17] both suggest that either one of the two criteria is sufficient for the PCL diagnosis. This has, to some extent, changed the field, and it may be difficult to compare some newer studies using the new criteria to older studies that used the old, strict definitions.

\section{Finding a Prognostic Threshold for Circulating Plasma Cells}

Identifying the most relevant threshold for circulating plasma cells to define PCL remains an interesting topic in PCL. The traditional cutoff set by Kyle et al. [10] was arbitrary, and several studies have questioned this cutoff $[11,12 \bullet, 13 \bullet]$. In 2013, it was suggested by the IMWG that thresholds for diagnosis should be reevaluated [25]. In 2017, Granell and coworkers [12•] explored $482 \mathrm{MM}$ and 5 PCL patients who were classified according to the amount of circulating plasma cells (CPC) into subgroups with $0 \%, 1-4 \%, 5-20 \%$, and PCL ( $\geq$ 20\%) [12•]. It was found that 12 patients with 5-20\% circulating plasma cells had a median overall survival of only 6 months. This was even lower than what was observed in the PCL patients, but the findings should of course be interpreted with caution, considering the small number of patients in the subgroups. Based on their data, Granell et al. suggested a cutoff of 5\% for the definition of PCL [12•]. Likewise, Gang et al. in 2014 compared 767 patients with MM to 33 patients with PCL [26•]. MM patients with circulating plasma cells as low as $2 \%$ in blood smears had progression free and overall survival rates comparable to those of the PCL patients [26•]. In a study from The Mayo Clinic 2014, using flow cytometry, it was found that as few as 400 clonal plasma cells per 150,000 events, corresponding to $0.26 \%$ circulating plasma cells, were highly significant for reduced overall survival [27]. 

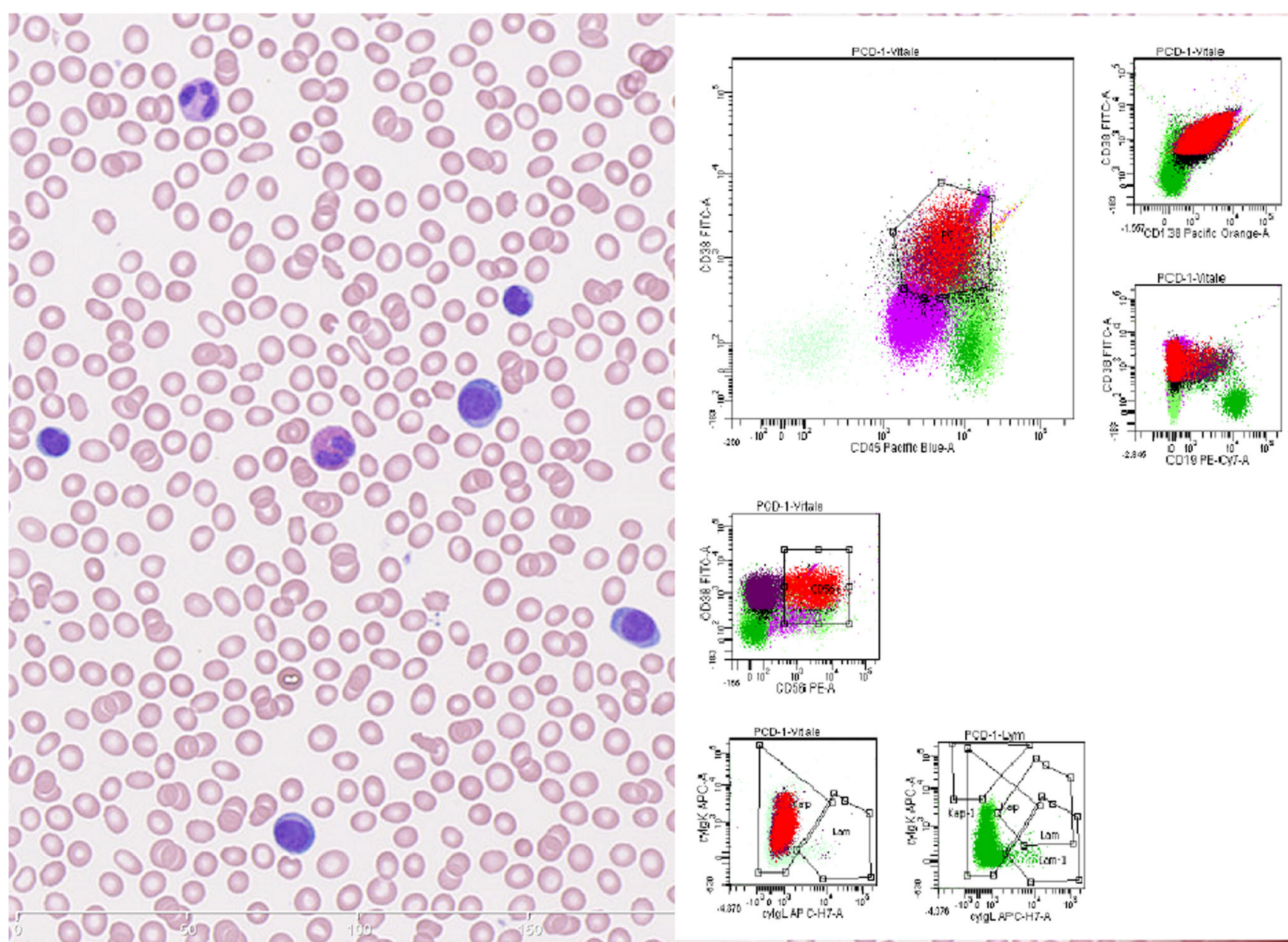

Fig. 1 Left: Blood smear showing plasma cells constituting $>20 \%$ of total leukocytes. The plasma cells are atypical with high nuclear/ cytoplasmic ratio. Right: flow cytometry histograms of blood. The

Also, in other settings, the prognostic impact of circulating plasma cells has been highlighted. At the time of ASCT, circulating plasma cells are indicative of short progression free survival [28]. In smoldering MM, it has been shown that circulating plasma cells identify patients with high risk of early progression to MM [13•]. Thus, several studies have shown that circulating plasma cells in $\mathrm{MM}$ at a threshold lower than $20 \%$ or $2 \times 10^{9}$ identify patients with a severe and PCL-like prognosis and thereby challenge the current definition of PCL. However, a new optimal threshold has still to be determined and defined in consensus.

\section{Clinical Presentation}

The clinical presentation of PCL differs from that of MM in several ways, and in Table 1, we have summarized the major differences. The median age at diagnosis is about 61 years, which is about 10 years less than in MM. Light chain only PCL is more common than in MM, being the second most
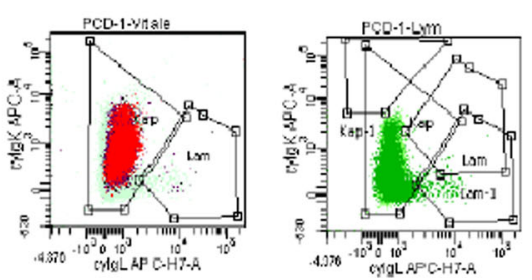

neoplastic plasma cells indicated in red and purple (CD56 positive and negative fraction respective) express CD138, bright CD38, CD45, cytoplasmic kappa and are negative for CD19 and cytoplasmic lambda

common subtype after the IgG subtype. Also, the nonsecretory subtype is more commonly observed in PLC [1, 13, 20-24]. Most PCL patients present with high tumor burden, e.g., $67 \%$ have International Staging System (ISS) stage 3 at diagnosis. Elevated lactate dehydrogenase (LDH) is common; most present with cytopenia and extramedullary involvement of the liver, spleen, and other organs besides the blood is common $[1,13 \bullet, 20 \bullet, 21 \bullet, 22 \bullet, 23 \bullet, 24 \bullet]$. Opposite, osteolyses are seen less frequently in PCL $[1,13 \bullet, 20 \bullet, 21 \bullet$, 22•, 23•, 24•]. Disease presentation of PCL has been compared to that of MM in Table 1 [29-34]. Considering the very high rate of extramedullary disease, IMWG has suggested that FDG-PET/CT should be considered in diagnosis, evaluation, and monitoring of PCL [25].

\section{Disease Biology}

The most characteristic cytogenetic findings in PCL are summarized in Table 1. Importantly, no mutations or other gene 
Table 1 Clinical characteristics and cytogenetics in primary plasma cell leukemia and multiple myeloma

\begin{tabular}{lll}
\hline Clinical characteristics at diagnosis & $\begin{array}{c}\text { Primary plasma } \\
\text { cell leukemia }\end{array}$ & $\begin{array}{c}\text { Multiple } \\
\text { myeloma }\end{array}$ \\
Male & $55 \%$ & $55 \%$ \\
Age (median) & 61.5 years & 69 years \\
IgG & $46 \%$ & $58 \%$ \\
IgA & $13 \%$ & $22 \%$ \\
Light chain only & $30 \%$ & $15 \%$ \\
Nonsecretory & $10 \%$ & $4 \%$ \\
Other & $1 \%$ & $1 \%$ \\
Anemia, Hgb $<10 \mathrm{~g} / \mathrm{dL}$ & $81 \%$ & $47 \%$ \\
Trombocytes $<130^{*}$ & $63 \%$ & $5 \%$ \\
Elevated creatinine** & $22 \%$ & $24 \%$ \\
Abnormal LDH*** & $60 \%$ & $12 \%$ \\
Hypercalcemia**** & $27 \%$ & $12 \%$ \\
Bone disease & $65 \%$ & $77 \%$ \\
ISS I & $10 \%$ & $27 \%$ \\
ISS II & $23 \%$ & $39 \%$ \\
ISS III & $67 \%$ & $34 \%$ \\
Cytogenetic findings at diagnosis & & $48 \%$ \\
Translocation $(11 ; 14)$ & $26 \%$ & $21 \%$ \\
Translocation $(4 ; 14)$ & $14 \%$ & $14 \%$ \\
Translocation $(14 ; 16)$ & $20 \%$ & $4 \%$ \\
Deletion $(17 \mathrm{p})$ & $40 \%$ & $11 \%$ \\
Whole/partial deletion $13 \mathrm{q}$ & $42 \%$ & $40 \%$ \\
Amplification $1 \mathrm{q}$ & $32 \%$ & \\
\hline & & \\
\hline
\end{tabular}

Data compounded from studies referenced below. *Some studies use thrombocytes $<100, * *$ Creatinine $>2 \mathrm{mg} / \mathrm{dl}$, ***Most studies are not defining limits of elevated $\mathrm{LDH}, * * * *$ Non ionized calcium $>$ $2.75 \mathrm{mmol} / 1$ or ionized calcium $>1.45 \mathrm{mmol} / 1$. References: [19•, 20•, $21 \bullet, 22 \bullet, 23 \bullet, 24 \bullet, 29,30,31,32,33,34,35 \bullet, 36]$

aberrations are specific for PCL compared to MM, but the relative occurrence of changes differs between PCL and MM (Table 1). Characteristic mutational patterns in PCL underline that PCL and MM are distinct entities, not only clinically but also genetically.

As in MM, translocations involving chromosome 14 , $\mathrm{t}(11 ; 14), \mathrm{t}(14 ; 16)$, and $\mathrm{t}(4 ; 14)$ are common in PCL $[19 \bullet, 20 \bullet$, $23 \cdot, 24 \cdot, 35 \cdot, 36]$. Of these $t(11 ; 14)$ is known to be of clinical importance in $\mathrm{MM}$ and other hematological diseases where it predicts sensibility to the bcl-2 inhibitor, venetoclax [37], while $\mathrm{t}(4 ; 14)$ and $\mathrm{t}(14 ; 16)$ are known to predict high-risk disease in MM [38].

TP53 and DIS3 mutations are more common in PCL than in MM, whereas NRAS, KRAS, and BRAF mutations are less frequently observed in PCL than in MM and SPCL [39]. A recent study using next-generation sequencing found that TP53 mutations were negatively associated with KRAS mutations and a predictor of more aggressive disease [40]. Besides being frequently mutated, TP53 located on $17 \mathrm{p} 13$ is also often deleted $[12 \bullet, 19 \bullet, 20 \bullet, 22 \bullet]$. Other deletions are also common in PCL, including 1p, 6q, 8p, 13q, 14q, and 16q [36]. MYC rearrangements have earlier been found to be commonly upregulated in PCL [41], which has also been found by Royer et al. [19•].

Very heterogeneous mutations and complex genotypes were found in a study employing whole-genome sequencing and gene expression analysis in 12 PCL cases [39]. The authors reported that the mutation patterns were more complex compared to what is observed in MM [39]. This finding has been confirmed by other groups $[23 \bullet, 24 \bullet, 35 \bullet$.

Data from RNA [42] and proteome studies [43] have been presented recently with focus on the transition from MM to SPCL. Ronchetti et al. studied RNA expression (especially long non-coding RNA) in MGUS, smoldering MM, MM, PCL, and SPCL [42]. Interestingly, they found that a number of long non-coding RNA's (lncRNA) were progressively deregulated as the dyscrasia entered a more severe stage, suggesting a possible role in the progression of dyscrasia. This indicates that although lncRNAs are, by nature, non-coding, they might have regulatory roles, though it is also possible that the finding is a mere byproduct of progression [42]. In the study by Zatula et al. [43], changes in the proteome during the transformation from MM to SPCL were reported.

\section{Treatment}

It has been reported in several studies that a significant number of patients with PCL die within few months after diagnosis $[19 \bullet, 20 \bullet, 21 \bullet, 22 \bullet, 23 \bullet, 24 \bullet]$. Due to the aggressive behavior of PCL, treatment should start as soon as possible. Treatment of PCL with traditional cytostatic chemotherapy has shown poor results. However, following the introduction of ASCT, the proteasome inhibitor bortezomib and the immuno-regulatory drugs thalidomide and lenalidomide, the prognosis has, to some extent, improved.

In a major retrospective registry study in 2014 from the SEER database, Gonsalves et al. investigated the overall survival in a total of 445 PCL cases through four time periods; 1973-1995, 1996-2000, 2001-2005, and 2006-2009 [1]. Thus, the study investigated the development in survival after the introduction of ASCT became widespread in 1995, thalidomide in 2000, and bortezomib and lenalidomide in the latter period. The OS observed was only 5, 6, 4, and 12 months in the different time periods. These data do not support improved survival with the usage of ASCT or allogenic stem cell transplantation (alloSCT) but possibly indicating effectiveness of bortzemib and lenalidomide. Improved survival with ASCT and/or alloSCT has however been shown in other studies as discussed later $[20 \bullet, 21 \bullet, 22 \bullet, 23 \bullet]$.

Very early death is a significant problem in PCL, but in the SEER data, it was also observed that the number of patients 
who died less than 1 month after diagnosis has decreased from $28 \%, 23 \%, 27 \%$, and $15 \%$, respectively, during the time periods. Unfortunately, in 2009, PCL and MM were grouped together in the SEER database, making more recent investigation difficult [1].

Fast responses, but frequent and early relapses are hallmarks of the treatment challenges in PCL $[1,13 \bullet, 20 \bullet, 21 \bullet$, $22 \bullet, 23 \bullet, 24 \bullet$. Tumor lysis syndrome at the start of treatment is not uncommon, and precautions should be made. Early effective treatment must be consolidated and maintained. Different strategies for this have been evaluated as discussed in the following sections. Standard maintenance known from MM is not likely to be sufficient $[1,13 \bullet, 20 \bullet, 21 \bullet, 22 \bullet, 23 \bullet$, $24 \cdot]$.

Table 2 presents a summary of the major clinical studies done on PCL.

\section{Bortezomib}

In MM, proteasome inhibition with bortezomib has shown the ability to (partly) overcome the prognostic adverse impact of high-risk cytogenetic aberrations such as $\mathrm{t}(4 ; 14), \mathrm{t}(14 ; 16)$, $\mathrm{t}(14 ; 20), \operatorname{del}(1 \mathrm{p})$, and del(17p) [44-46]. Adverse cytogenetic findings are common in PCL, and bortezomib might be particularly well suited to include in the treatment. The first major study showing promising results was conducted by the GIMEMA group in 2012 [47]. In 2016, a French prospective phase 2 study tested the efficacy of bortezomib in combination with dexamethasone, and either doxyrubicin or cyclophosphamide followed by high-dose melphalan and ASCT. This study showed a high overall response rate $(69 \%)$ and OS of 36.3 months [19•]. Most retrospective studies have supported an important role of bortezomib in PCL treatment [21•, 23•, $24 \cdot$ ]; only an Israeli study did not report improved survival after treatment with bortezomib or carfilzomib [20•]. The results of these studies are summarized in Table 2.

\section{Thalidomide and Lenalidomide}

Thalidomide and lenalidomide are IMIDs (immune modulatory drugs) that for several years have been the backbone in MM treatment. The first prospective study of lenalidomide in PCL was reported in 2014 by Musto et al. and showed an overall high response rate of lenalidomide in combination with low-dose dexamethasone [22•]. In other studies, thalidomide and lenalidomide have been found to increase survival in combination with or comparable to bortezomib $[23 \bullet, 35 \bullet$. A particular role for lenalidomide and other IMIDs could be to maintain achieved response after initial treatment, and for enhancing graft-versus-leukemia effect after allo-SCT [20•].

\section{ASCT}

Two prospective phase 2 studies have indicated that ASCT is able to prolong PFS and OS in PCL [19•, 22•]. Also, several recently published retrospective studies including populationbased data reported improved PFS and OS in ASCT-treated patients $\left[20^{\bullet}, 21 \bullet, 23 \bullet\right]$. The findings in these studies are summarized in Table 2.

\section{AlloSCT}

AlloSCT, unlike ASCT, employs the graft versus leukemia effect and is used to obtain cure in some hematological diseases. In a retrospective study from the Center for International Blood and Marrow Transplant Research, it was reported that both ASCT and alloSCT seem to improve survival; however, ASCT showed better OS rates [48]. In the prospective French trial, it was also observed that ASCT patients in fact had better PFS and OS compared to allo-treated patients [19•, 49].

\section{AlloSCT Compared to ASCT}

So far, published data seem to favor ASCT compared to alloSCT. However, no prospective studies have made a direct comparison. AlloSCT has mostly been used in combination with ASCT, using ASCT to deepen response before alloSCT administered with reduced intensity conditioning [19•, 20•, 22•]. The poorer reported results with alloSCT could partly be caused by selection bias where patients with particularly aggressive disease behavior have been allotransplanted. Another reason for poorer outcome after alloSCT is high treatment-related mortality. Historically, this has been high, but within the last decennium, it has decreased. The potential role of alloSCT has not been finally settled. Graft-versustumor effect after donor lymphocyte infusion has been documented in MM [50, 51], but could be less in PCL. PostSCT maintenance could improve disease control until the GVL effect is mature, and moreover, lenalidomide, other IMId, or immunotherapy could enhance the GVL effect [52]. Ongoing trials, including the European primary PCL study (EudraCT number 2013-005157-75) will contribute to clarify the role of alloSCT in PCL.

\section{Maintenance Treatment}

Early progression of PCL after achieved remission is the norm even after deep responses. Therefore, maintenance therapy is needed after ASCT and after end of induction in patients not eligible for ASCT. In the prospective study by Musto et al., maintenance treatment was given as lenalidomide $10 \mathrm{mg} /$ day 1-21 of 28-day cycles. Still, $50 \%$ of patients relapsed within 12 months after the start of maintenance [22•]. In the French 


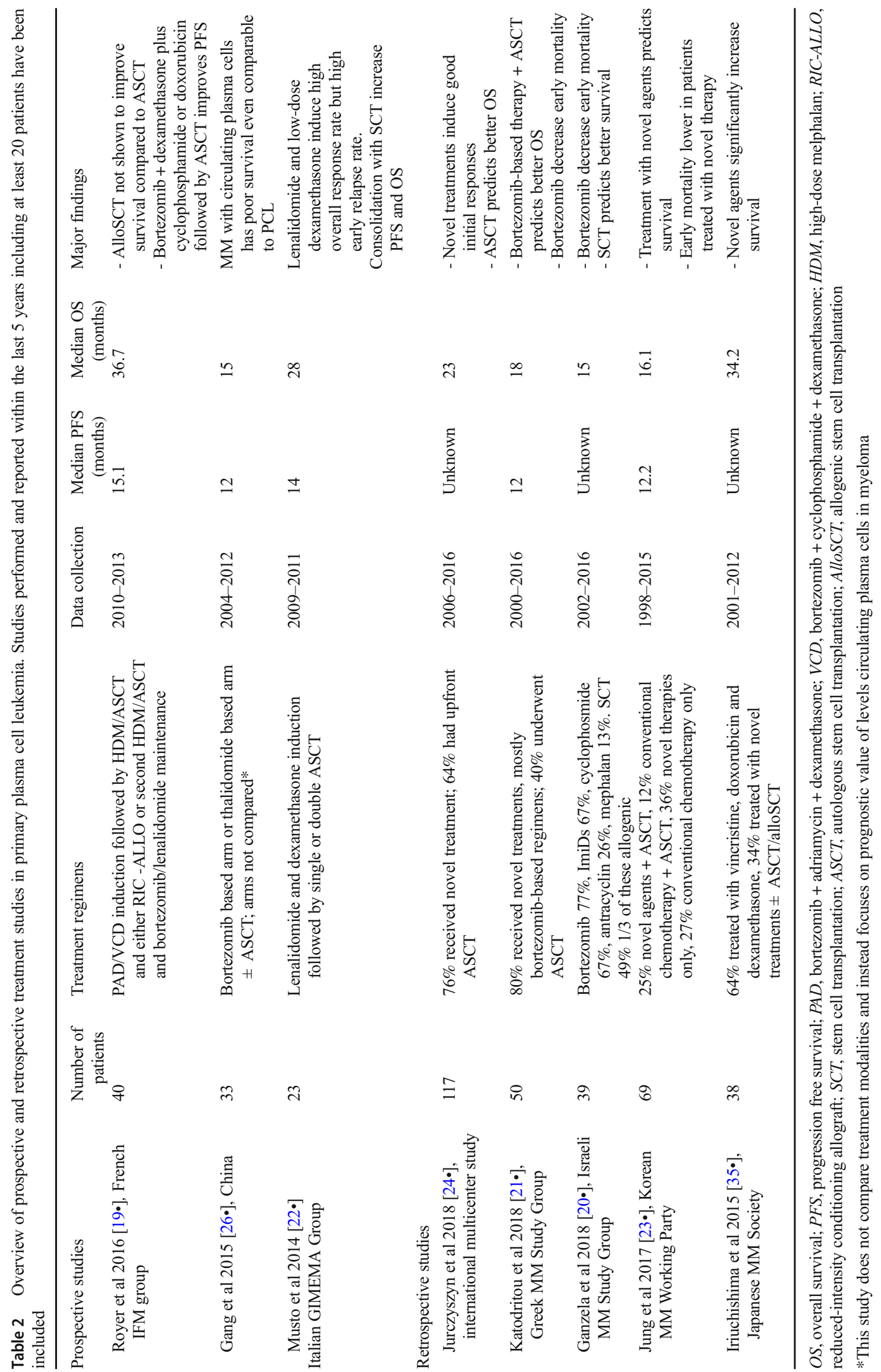


prospective study, lenalidomide, bortezomib, and dexamethasone were given as maintenance. Only one of seven patients relapsed during the study period; three had to stop maintenance therapy due to prolonged cytopenia [19•]. In a Japanese retrospective study, it was reported that patients who received maintenance with bortezomib, thalidomide, or lenalidomide tended to have longer OS, 4.5 versus 2.9 years, though the number of patients was too small for this to be significant [35•]. The low numbers of included patients in studies make definite conclusions difficult. However, the current best strategy for maintaining PCL patients in remission seems to be giving a combination of bortezomib and lenalidomide.

\section{Treatment of sPCL}

For SPCL, studies are extremely limited, and patients are often heavily pretreated. A recent study indicated improved prognosis by treatment with bortezomib-containing regimens. The study reported the most important factor to be high quality first response to treatment [53]. A recent, small study further investigated treatment of sPCL with bortezomib and lenalidomide-containing regimen achieving PFS of more than 27 months in $2 / 9$ pts. [54]. As in MM, treatments with thalidomide and lenalidomide are likely to have some effect on SPCL, but patients will often already have received these treatments [54]. ASCT has been used for SPCL. The survival was still poor, but a few patients achieved remission for more than 1 year [54].

\section{New and Upcoming Treatments and Studies}

Venetoclax is a BCL-2 inhibitor that has demonstrated remarkable efficacy in MM, CLL, and other hematological diseases harboring the $(11 ; 14)$ translocation [37]. As noted earlier, this particular translocation is common in PCL. In a recent case report, venetoclax was used in combination with daratumumab, dexamethasone, and bortezomib in a $t(11 ; 14)$ refractory PCL patient resulting in a rapid and deep response already after the first treatment cycle [55].

Pomalidomide is a third-generation IMID that has shown good response and survival benefit in refractory MM [56, 57]. In a case report, a PCL patient with CNS relapse after allogenic SCT was successfully treated with cerebral radiation and intrathecal chemotherapy followed by pomalidomide and dexamethasone maintenance. At the time of reporting, the patient was still in remission after 18 months of follow-up [58]. In another case report, a patient with SPCL achieved normalization of hematological values and significant decrease in M-component after 4-month treatment combining low-dose dexamethasone and pomalidomide [59].

Ixazomib is a second-generation PI used in combination with lenalidomide and dexamethasone in relapsed or refractory MM $[60,61]$. Ixazomib is currently being investigated in a phase $1 \mathrm{~b}$ study as maintenance treatment after alloSCT in relapsed high-risk MM included patients with $\mathrm{SPCL}$ and PCL (NCT02504359) [62]. An ongoing phase II study from the Mayo Clinic investigates the efficacy of combining ixazomib, pomalidomide, and dexamethasone for SPCL or previously treated MM (NCT02547662) [63].

Carfilzomib, another second-generation PI, combined with lenalidomide and dexamethasone is currently being tested as induction treatment of PCL in a European multi-center study (EudraCT number 2013-005157-75). Responding transplant eligible patients are subsequently treated with ASCT followed by allo-SCT, and hereafter maintained with low-dose lenalidomide to increase GVL effect.

Daratumumab is an anti-CD38 antibody which, in several studies, has shown impressive efficacy in relapsed, refractory MM. Daratumumab and other anti-CD38 antibodies will for sure be of high interest to study in PCL and sPCL (NCT03591744) [64].

The use of anti-CD45 antibodies is currently being investigated for high-risk myeloma, [65], and other antibodiestargeting CD75s are currently being investigated for their ability to bind MM and PCL cells [66].

BRAF/MEK inhibitors are newly developed compounds that are used successfully for targeted treatment of malignant melanoma [67] and MM [68]. BRAF pathway mutations are seen in about 5-6\% of MM patients, whereas BRAF pathway mutations are less frequently observed in PCL compared to SPCL and MM. The treatment principle of combining BRAF and MEK inhibitors will be an interesting option in the treatment of BRAF pathway-mutated PCL or SPCL patients [68].

CAR-T therapy is an exciting new technique using genetically engineered autologous $\mathrm{T}$ cells that are programmed to bind specific antigens on target cells. Encouraging results have been found in lymphomas and leukemia and also in MM [69]. Data in the PCL setting is pending.

Peptide vaccination studies have so far not fulfilled their promises in MM. However, studies are ongoing, also including PCL patients [70].

\section{Conclusion}

In conclusion, the diagnostic criteria of PCL are under discussion in the international myeloma community. Both primary and particularly secondary PCL are very aggressive diseases with adverse prognoses. Secondary PCL is often treatment resistant, whereas early and even deep responses are common in primary PCL, but early relapses and development of resistance are typical. Treatment should start promptly with an effective proteasome inhibitor-containing regimen and followed by high-dose chemotherapy and ASCT in eligible patients. A strategy for further semi-intensive consolidation and continued maintenance should always be considered. 
AlloSCT has so far shown less encouraging results, but might be considered in younger patients. A number of new treatment modalities are currently being investigated and will hopefully be able to improve the prognosis in this devastating disease.

\section{Compliance with Ethical Standards}

Conflict of Interest The authors declare that they have no conflict of interest.

Human and Animal Rights and Informed Consent All reported studies/ experiments with human or animal subjects performed by the authors have been previously published and complied with all applicable ethical standards (including the Helsinki Declaration and its amendments, institutional/national research committee standards, and international/national/institutional guidelines).

Abbreviations $\quad P C L$, Primary plasma cell leukemia; $M M$, Multiple myeloma; $s P C L$, Secondary plasma cell leukemia; PI, Proteasome inhibitor; $O S$, Overall survival; $P F S$, Progression-free survival; IMID, Immunomodulatory drugs; $S C T$, Stem cell transplantation; $A S C T$, Autologous stem cell transplantation; alloSCT, Allogeneic stem cell transplantation

Open Access This article is distributed under the terms of the Creative Commons Attribution 4.0 International License (http:// creativecommons.org/licenses/by/4.0/), which permits unrestricted use, distribution, and reproduction in any medium, provided you give appropriate credit to the original author(s) and the source, provide a link to the Creative Commons license, and indicate if changes were made.

Publisher's Note Springer Nature remains neutral with regard to jurisdictional claims in published maps and institutional affiliations.

\section{References}

Papers of particular interest, published recently, have been highlighted as:

- Of importance

1. Gonsalves WI, Rajkumar SV, Go RS, Dispenzieri A, Gupta V, Singh $\mathrm{PP}$, et al. Trends in survival of patients with primary plasma cell leukemia: a population-based analysis. Blood. 2014;124:907-12.

2. Sant M, Allemani C, Tereanu C, Angelis RD, Capocaccia R, Visser $\mathrm{O}$, et al. Incidence of hematologic malignancies in Europe by morphologic subtype: results of the HAEMACARE project. Blood. 2010;116:3724-34.

3. Dimopoulos MA, Palumbo A, Delasalle KB, Alexanian R. Primary plasma cell leukaemia. Br J Haematol. 1994;88:754-9.

4. García-Sanz R, Orfao A, González M, Tabernero MD, Bladé J, Moro MJ, et al. Primary plasma cell leukemia: clinical, immunophenotypic, DNA ploidy, and cytogenetic characteristics. Blood. 1999;93:1032-7.

5. Ramsingh G, Mehan P, Luo J, Vij R, Morgenstern D. Primary plasma cell leukemia: a surveillance, epidemiology, and end results database analysis between 1973 and 2004. Cancer. 2009;115:5734-9.

6. Tiedemann RE, Gonzalez-Paz N, Kyle RA, Santana-Davila R, Price-Troska T, Van Wier SA, et al. Genetic aberrations and survival in plasma cell leukemia. Leukemia. 2008;22:1044-52.
7. Gimsing P, Holmström MO, Klausen TW, Andersen NF, Gregersen $\mathrm{H}$, Abildgaard N, et al. The Danish National Multiple Myeloma Registry. Clin Epidemiol. 2016;25:583-7.

8. Turesson I, Bjorkholm M, Blimark CH, Kristinsson S, Velez R, Landgren $\mathrm{O}$. Rapidly changing myeloma epidemiology in the general population: increased incidence, older patients, and longer survival. Eur J Haematol. 2018;101:237-44. https://doi.org/10.1111/ ejh. 13083.

9. Keats J, Chesi M, Egan JB, Garbitt VM, Palmer SE, Braggio E, et al. Clonal competition with alternating dominance in multiple myeloma. Blood. 2012;120:1067-76.

10. Kyle RA, Maldonado JE, Bayrd ED. Plasma cell leukemia. Report on 17 cases. Arch Intern Med. 1974;133:813-8.

11. Bezdekova R, Penka M, Hajek R, Rihova L. Circulating plasma cells in monoclonal gammopathies. Klin Onkol. 2017;30(Supplementum2): 29-34. https://doi.org/10.14735/amko20172S29.

12. Granell M, Abella E, Senín A, Calvo X, Garcia-Guiñón A, Martínez CM, et al. Prognostic impact of circulating plasma cells in patients with multiple myeloma: implications for plasma cell leukemia definition. Haematologica. 2017;102:1099-104 Major negative prognostic impact of circulating plasma cells in multiple myeloma which challenges the definition of plasma cell leukemia.

13. Gonsalves WI, Rajkumar SV, Dispenzieri A, Dingli D, Timm MM, Morice WG, et al. Quantification of circulating clonal plasma cells via multiparametric flow cytometry identifies patients with smoldering multiple myeloma at high risk of progression. Leukemia. 2017;31:130-5 Prognostic impact of circulating plasma cells, especially for progression of smoldering myeloma.

14. Shtalrid M, Shvidel L, Vorst E. Polyclonal reactive peripheral blood plasmacytosis mimicking plasma cell leukemia in a patient with staphylococcal sepsis. Leuk Lymphoma. 2007;44:379-80.

15. Touzeau C, Pellat-Deceunynck C, Gastinne T, Accard F, Jego G, Avet-Loiseau H, et al. Reactive plasmacytoses can mimick plasma cell leukemia: therapeutical implications. Leuk Lymphoma. 2007;48:207-8.

16. Lee TG, Jeong WS, Moon SH, Hwangbo H, Lee SK, Lee DR, et al. Cutaneous and systemic plasmacytosis associated with renal amyloidosis. Ann Dermatol. 2015;27:759-62.

17. Swerdlow SH, Campo E, Harris NL, Jaffe ES, Pileri SA, Stein H, Thiele J (Eds): WHO Classification of Tumours of Haematopoietic and Lymphoid Tissues (Revised 4th edition). IARC: Lyon 2017.

18. Fulwyler MJ. Electronic separation of biological cells by volume. Science. 1965;150:910-1.

19. Royer B, Minvielle S, Diouf M, Roussel M, Karlin L, Hulin C, et al. Bortezomib, doxorubicin, cyclophosphamide, dexamethasone induction followed by stem cell transplantation for primary plasma cell leukemia: a prospective phase II study of the Intergroupe Francophone du Myélome. J Clin Oncol. 2016;34:2125-32 Major prospective clinical trial investigating the effect of induction treatment with bortezomib and dexamethasone plus doxorubicin or cyclophosphamide followed by stem cell transplantation (SCT) in primary plasma cell leukemia. Allogeneic SCT not shown to improve survival compared to autologous SCT.

20. Ganzela C, Rouviob O, Avivic I, Hila M, Jarchowskye O, Herzogf $\mathrm{K}$, et al. Primary plasma cell leukemia in the era of novel agents for myeloma - a multicenter retrospective analysis of outcome. Leuk Res. 2018;68:9-14 Major retrospective study of the impact of novel drugs in the treatment of primary plasma cell leukemia. Bortezomib decreases early mortality.

21. Katodritou E, Terpos E, Delimpasi S, Kotsopoulou M, Michalis E, Vadikolia C, et al. Real-world data on prognosis and outcome of primary plasma cell leukemia in the era of novel agents: a multicenter national study by the Greek Myeloma Study Group. Blood Cancer J. 2018;8:31 Major retrospective study of the impact of novel drugs in the treatment of primary plasma cell 
leukemia.Bortezomib based induction treatment and autologous stem cell transplantation associated to better survival.

22. Musto P, Simieon V, Martorelli MC, Petrucci MT, Cascavilla N, Raimondo FD, et al. Lenalidomide and low-dose dexamethasone for newly diagnosed primary plasma cell leukemia. Leukemia. 2014;28:222-5 Lenalidomide and low dose dexamethasone induce high overall response rate but early relapse rate is high. Consolidation with SCT increase PFS and OS.

23. Jung SH, Lee JJ, Kim K, Suh C, Yoon DH, Min CK, et al. The role of frontline autologous stem cell transplantation for primary plasma cell leukemia: a retrospective multicenter study (KMM160). Oncotarget. 2017;8:79517-26 Major retrospective study of the impact of novel drugs in the treatment of primary plasma cell leukemia. Treatment with novel agents is associated to diminished early mortality and improved survival.

24. Jurczyszyn A, Radocha J, Davila J, Fiala MA, Gozzetti A, et al. Prognostic indicators in primary plasma cell leukaemia: a multicentre retrospective study of 117 patients. Br J Haematol. 2018;180:831-9 Largest recent retrospective study of primary plasma cell leukemia. Novel treatments induce good initial responses and autologous stem cell transplantation associated to better overall survival.

25. De Larrea CF, Kyle RA, Durie BGM, Ludwig H, Usmani S, Vesole $\mathrm{DH}$, et al. Plasma cell leukemia: consensus statement on diagnostic requirements, response criteria, and treatment recommendations by the International Myeloma Working Group (IMWG). Leukemia. 2013;27:780-91

26. An G, Qin X, Acharya C, Xu Y, Deng S, Shi L, et al. Multiple myeloma patients with low proportion of circulating plasma cells had similar survival with primary plasma cell leukemia patients. Ann Hematol. 2015;94:257-64 Prognostic impact of circulating plasma cells on survival in multiple myeloma patients.

27. Gonsalves WI, Rajkumar SV, Gupta V, Morice WG, Timm MM, Singh PP, et al. Quantification of clonal circulating plasma cells in newly diagnosed multiple myeloma: implications for redefining highrisk myeloma. Leukemia. 2014;28:2060-5.

28. Cowan AJ, Stevenson PA, Libby EN, Becker PS, Coffey DG, Damian J, et al. Circulating plasma cells at the time of collection of autologous PBSC for transplant in multiple myeloma patients is a negative prognostic factor even in the age of post-transplant maintenance therapy. Biol Blood Marrow Transplant. 2018;24:1386-91. https://doi.org/10.1016/j.bbmt.2018.02.017.

29. Blimark CH, Turesson I, Genell A, Ahlberg L, Björkstrand B, Carlson K, et al. Collaborative Groups: The Swedish Myeloma Registry. Outcome and survival of myeloma patients diagnosed 2008-2015. Real world data on 4904 patients from the Swedish Myeloma Registry (SMR). Haematologica. 2017(103):506-13.

30. Roman Hájek JJ, Maisnar V, Pour L, Spicka I, Minarík J, et al. Realworld outcomes of multiple myeloma: retrospective analysis of the Czech Registry of Monoclonal Gammopathies. Clin Lymphoma Myeloma Leuk. 2018;18:e219-40. https://doi.org/10.1016/j.clml. 2018.04.003.

31. Sonneveld P, Avet-Loiseau H, Lonial S, Usmani S, Siegel D, Anderson $\mathrm{KC}$, et al. Treatment of multiple myeloma with highrisk cytogenetics: a consensus of the International Myeloma Working Group. Blood. 2016;127:2955-62.

32. Palumbo A, Avet-Loiseau H, Oliva S, Henk M, Goldschmidt H, et al. Revised international staging system for multiple myeloma: a report from International Myeloma Working Group. J Clin Oncol. 2015;33:2863-9.

33. Kyle RA, Gertz MA, Witzig TE, Lust JA, Lacy MQ, Dispenzieri A, et al. Review of 1027 patients with newly diagnosed multiple myeloma. Mayo Clin Proc. 2003;78:21-33.

34. Bergsagel PL, Kuehl WM, Zhan F, Sawyer J, Barlogie B, Shaughnessy J. Cyclin D dysregulation: an early and unifying pathogenic event in multiple myeloma. Blood. 2005;106:296-303.
35. Iriuchishima I, Ozaki S, Konishi J, Matsumoto M, Murayama K, Nakamura F, et al. Primary plasma cell leukemia in the era of novel agents: a multicenter study of the Japanese Society of Myeloma. Acta Haematol. 2016;135:113-21 Retrospective study of the impact of novel drugs in the treatment of primary plasma cell leukemia. Use of novel drugs associated to better survival.

36. Mosca L, Musto P, Todoerti K, Barbieri M, Agnelli L, Fabris S, et al. Genome-wide analysis of primary plasma cell leukemia identifies recurrent imbalances associated with changes in transcriptional profiles. Am J Hematol. 2013;88:16-23.

37. Mihalyova J, Jelinek T, Growkova K, Hrdinka M, Simicek M, Hajek R. Venetoclax: a new wave in hematooncology. Exp Hematol. 2018;61:10-25.

38. Joseph NS, Gentili S, Kaufman JL, Lonial S, Nooka AK. High-risk multiple myeloma: definition and management. Clinical Lymph Myelom Leukemia. 2017;17:S80-S7.

39. Cifola I, Lionetti M, Pinatel E, Todoerti K, Mangano E, Pietrelli A, et al. Whole-exome sequencing of primary plasma cell leukemia discloses heterogeneous mutational patterns. Oncotarget. 2015;6: 17543-58.

40. Lionetti M, Barbieri M, Manzoni M, Fabris S, Bandini C, Todoerti $\mathrm{K}$, et al. Molecular spectrum of TP53 mutations in plasma cell dyscrasias by next generation sequencing: an Italian cohort study and overview of the literature. Oncotarget. 2016;7:21353-61.

41. Chiecchio LDG, White HE, Towsend MR, Protheroe RK, Cheung $\mathrm{KL}$, et al. Frequent upregulation of MYC in plasma cell leukemia. Genes Chromosom Cancer. 2009;48:624-36.

42. Ronchetti D, Agnelli L, Taiana E, Galletti S, Manzoni M, Todoerti $\mathrm{K}$, et al. Distinct lncRNA transcriptional fingerprints characterize progressive stages of multiple myeloma. Oncotarget. 2016;7: 14814-30.

43. Zatula A, Dikic A, Mulder C, Sharma A, Vågbø CB, Sousa MML, et al. Proteome alterations associated with transformation of multiple myeloma to secondary plasma cell leukemia. Oncotarget. 2017;8:19427-42

44. Le Blanc R, Ahmad I, Terra R, Landais S, Sebag M, LemieuxBlanchard E, et al. Bortezomib consolidation after nonmyeloablative allogeneic stem cell transplantation leads to a high Incidence of immunophenotypic complete response in young and/or high-risk multiple myeloma patients. Blood. 2016;128:2306.

45. Nooka AK, Kaufman JL, Muppidi S, Langston A, Heffner LT, Gleason $\mathrm{C}$, et al. Consolidation and maintenance therapy with lenalidomide, bortezomib and dexamethasone (RVD) in high-risk myeloma patients. Leukemia. 2014;28:690-3.

46. An G, Acharya C, Deng S, Yi S, Xu Y, Qin X, et al. Cytogenetic and clinical marks for defining high-risk myeloma in the context of bortezomib treatment. Exp Hematol. 2015;43:168-76.

47. D'Arena G, Valentini CG, Pietrantuono G, Guariglia R, Martorelli MC, Mansueto G, et al. Frontline chemotherapy with bortezomibcontaining combinations improves response rate and survival in primary plasma cell leukemia: a retrospective study from GIMEMA Multiple Myeloma Working Party. Ann Oncol. 2012;23:1499-502.

48. Mahindra A, Kalaycio ME, Vela-Ojeda J, Vesole DH, Zhang MJ, Li $\mathrm{P}$, et al. Hematopoietic cell transplantation for primary plasma cell leukemia: results from the Center for International Blood and Marrow Transplant Research. Leukemia. 2012;26:1091-7.

49. Royer B, Diouf M, Roussel M, Karlin L, Hulin C, Arnulf B, et al. Long term follow-up of hematopoietic stem cell transplantation (HSCT) for primary plasma cell leukemia (pPCL): final results of a prospective study of IFM group. Blood. 2016;128:4612.

50. Beitinjaneh AM, Saliba R, Bashir Q, Shah N, Parmar S, Hosing C, et al. Durable responses after donor lymphocyte infusion for patients with residual multiple myeloma following nonmyeloablative allogeneic stem cell transplant. Leuk Lymphoma. 2012;53:1525-9. 
51. Gröger M, Gagelmann N, Wolschke C, Von Pein UM, Klyuchnikov E, Christopeit M, et al. Long-term results of prophylactic donor lymphocyte infusions for patients with multiple myeloma after allogeneic stem cell transplantation. Biol Blood Marrow Transplant. 2018;24:1399-405.

52. Lioznov M, El-Cheikh J, Hoffmann F, Hildebrandt Y, Ayuk F, Wolschke C, et al. Lenalidomide as salvage therapy after alloSCT for multiple myeloma is effective and leads to an increase of activated NK (NKp44(+)) and T (HLA-DR(+)) cells. Bone Marrow Transplant. 2010;45:349-53.

53. Katodritou E, Terpos E, Kelaidi C, Kotsopoulou M, Delimpasi S, Kyrtsonis MC, et al. Treatment with bortezomib-based regimens improves overall response and predicts for survival in patients with primary or secondary plasma cell leukemia: analysis of the Greek myeloma study group. Am J Hematol. 2014;89:145-50.

54. Jimenez-Zepeda VH, Reece DE, Trudel S, Chen C, Tiedemann R, Kukreti V. Lenalidomide (Revlimid), bortezomib (Velcade) and dexamethasone for the treatment of secondary plasma cell leukemia. Leuk Lymphoma. 2015;56:232-5.

55. Gonsalves WI, Buadi FK, Kumar SK. Combination therapy incorporating Bcl-2 inhibition with Venetoclax for the treatment of refractory primary plasma cell leukemia with $\mathrm{t}(11 ; 14)$. Eur J Haematol. 2018;100:215-7.

56. Gueneau P, Chretien ML, Cransac-Miet A, Aho LS, Lafon I, Favennec C, et al. Efficacy, safety, and cost of pomalidomide in relapsed and refractory multiple myeloma. Eur J Haematol. 2018;100:518-25.

57. Miguel JS, Weisel MP, Lacy M, Song K, Delforge M, et al. Pomalidomide plus low-dose dexamethasone versus high-dose dexamethasone alone for patients with relapsed and refractory multiple myeloma (MM-003): a randomised, open-label, phase 3 trial. Lancet. 2013;14:1055-66.

58. Yamashita Y, Tamura S, Oiwa T, Kobata H, Kuriyama K, Mushino $\mathrm{T}$, et al. Successful intrathecal chemotherapy combined with radiotherapy followed by pomalidomide and low-dose dexamethasone maintenance therapy for a primary plasma cell leukemia patient. Hematol Rep. 2017;23:28-31.

59. Mele G, Coppi MR, Guaragna G, Spina A, Melpignano A. Response to pomalidomide plus fixed low-dose dexamethasone in a case of secondary plasma cell leukaemia. Leuk Res. 2016;40: 30-2. https://doi.org/10.1016/j.leukres.2015.11.009.

60. Touzeau C, Moreau P. Ixazomib in the management of relapsed multiple myeloma. Future Oncol. 2018.
61. Moreau P, Masszi T, Grzasko N, Bahlis NJ, Hansson M, Pour $\mathrm{L}$, et al. Oral ixazomib, lenalidomide, and dexamethasone for multiple myeloma for the TOURMALINE-MM1 Study Group. N Engl J Med. 2016;374:1621-34. https://doi.org/10.1056/ NEJMoa1516282.

62. Combination Chemotherapy and Donor Stem Cell Transplant Followed by Ixazomib Citrate Maintenance Therapy in Treating Patients With Relapsed High-Risk Multiple Myeloma. https:// www.clinicaltrials.gov/ct2/show/NCT02504359?term $=$ NCT02504359.\&rank=1. Accessed 17 Apr 2018

63. Pomalidomide, Ixazomib Citrate, and Dexamethasone in Treating Patients With Previously Treated Multiple Myeloma or Plasma Cell Leukemia. www.clinicaltrials.gov:NCT02547662. Accessed 17 Apr 2018

64. Daratumumab, Bortezomib, Dexamethasone, Pegylated Liposomal Doxorubicin Hydrochloride, and Lenalidomide in Treating Participants With Plasma Cell Leukemia. www.clinicaltrials.gov: NCT03591744. Accessed 23 Apr 2018

65. Tuazon SA. A Phase 1 Trial of 90Y-BC8-DOTA (anti-CD45) monoclonal antibody in combination with Fludarabine and TBI as conditioning for Allogenic Peripheral Blood Stem Cell transplant to Treat High Risk Multiple Myeloma. www.clinicaltrials.gov: NCT01503242. Accessed 23 Apr 2018

66. Klausz K, Buck M, Krohn S, Burger R, Kellner C, Gramatzki M, et al. CD75s represents a therapeutic target for antibody-based immunotherapy of B cell lymphoma and multiple myeloma. Blood. 2017;130:1810.

67. Wahid M, Jawed A, Mandal RK, Dar SA, Akhter N, Somvanshi P, et al. Recent developments and obstacles in the treatment of melanoma with BRAF and MEK inhibitors. Crit Rev Oncol Hematol. 2018;125:84-8.

68. Mey UJM, Renner C, Von Moos R. Vemurafenib in combination with cobimetinib in relapsed and refractory extramedullary multiple myeloma harboring the BRAF V600E mutation. Hematol Oncol. 2017;35:890-3.

69. Mikkilineni L, Kochenderfer JN. Chimeric antigen receptor T-cell therapies for multiple myeloma. Blood. 2017;130:2594-602.

70. SVN53-67/M57-KLH Peptide Vaccine in Treating Patients With Newly Diagnosed Multiple Myeloma Receiving Lenalidomide Maintenance Therapy. www.clinicaltrials.gov:NCT02334865. Accessed 17 Apr 2018 